\title{
Analysing the Selection of Appropriate Technical Solutions for Nurses in a Clinical Setting
}

\author{
Nicole HECHTEL ${ }^{\mathrm{a}, 1}$, Jörn KRÜCKEBERG ${ }^{\mathrm{a}}$, Maria SEBASTIÃO ${ }^{\mathrm{b}}$ and Ronny \\ KLAWUNN $^{\mathrm{c}}$ \\ a Peter L. Reichertz Institute for Medical Informatics, University of Braunschweig- \\ Institute of Technology and Hannover Medical School \\ ${ }^{\mathrm{b}}$ Institute of General Practice, Universitätsklinikum Erlangen \\ ${ }^{c}$ Institute for Epidemiology, Social Medicine and Health Systems Research, Hannover \\ Medical School
}

\begin{abstract}
This work focuses the selection of technical solutions for professional nursing in a clinical setting. For a participatory approach the needs of the nursing staff are queried and analysed. Supplemented by data of patients a baseline for the selection of technical solutions is created.
\end{abstract}

Keywords. Nursing technology, participatory management

\section{Introduction}

Despite ongoing developments of technical solutions in the healthcare sector, specific solutions are not widespread in the daily work routine of professional nurses. Therefore different factors are focused in current discussions: on the one hand structural and outcome-related topics are explored [1, 2], on the other hand the technical application by users is discussed [3, 4]. The project center of implementing nursing care innovations (PPZ Hannover) ${ }^{2}$ aims to integrate innovative technologies to support nursing staff and to improve patient care. It thereby focuses a participatory approach to involve the nursing staff in the selection and implementation of technology [5].The participatory concept is based on the assessment of needs of the nursing staff. Derived from the results and by considering clinical conditions of the ward patients possible technical solutions for an implementation are identified. The aim of this paper is to provide and discuss an approach, how to select appropriate nursing technology in this specific setting.

\footnotetext{
${ }^{1}$ Corresponding Author: Nicole Hechtel, Peter L. Reichertz Institute for Medical Informatics, University of Braunschweig - Institute of Technology and Hannover Medical School, Hannover Medical School, Karl-Wiechert-Allee 3, 30625 Hannover, Germany; E-mail: nicole.hechtel@plri.de

${ }^{2}$ Funded by the German Ministry of Education and Research, grant number: 16SV7892K
} 


\section{Methods}

The project takes place at the Hannover Medical School on a ward of trauma surgery and integrates the whole nursing staff. Workshops were held for all nurses $(n=14)$ in order to identify and discuss needs in the current work situation as well as possible technical solutions [6]. The group discussion was recorded in writing and the results were presented to the nurses during the workshops. In this way, it was possible to ensure that all content was correctly reproduced. The qualitative data were analysed [7] and assigned to defined categories [8]: technical infrastructure, concern regarding patients, working procedures at the ward, working procedures at the hospital, constructional conditions and concern regarding physicians.

Additional clinical secondary data of patients at the ward for the period between January and December 2018 were analysed concerning sex, age and diagnoses to consider their conditions. Based on these data possible available technical solutions were identified by market research.

\section{Results}

\subsection{Needs in the current work situation of the nursing staff}

Based on the data of the workshops a range of 76 needs in the current work situation were identified and categorized. Concerning the aim of this project to support the nursing staff and to improve the patient care by innovative technology at the ward the following two categories were analysed in relation to possible technical solutions: concern regarding patients and working procedures at the ward. The other categories were not further focused because they are not addressing the mentioned aim of the project. The category concern regarding patients includes knowledge (e.g. professional training) and time-consuming needs (e. g. increased assistance, danger of falls, positioning of patients). The category working procedures at the ward includes needs like the disturbance of the workflow, the management of patients, walking distance for nurses or the light configuration (see Figure 1).

\subsection{Patient conditions}

The clinical secondary data of patients at the trauma surgery ward of the given period show that 1334 patients are treated, 678 male $(50,8 \%)$ and 656 female $(49,2 \%)$. The age is in mean 56,24 years with a standard deviation of 20,41 years and a median of 57 years. Accumulation can be seen between the age of 50 and 79 years (see Table 1).

Table 1. Age distribution of patients in 2018 at the trauma surgery ward

\begin{tabular}{cc}
\hline Age (years) & Count (patients) \\
\hline $0-19$ & 30 \\
$20-29$ & 142 \\
$30-39$ & 146 \\
$40-49$ & 150 \\
$50-59$ & 278 \\
$60-69$ & 206 \\
$70-79$ & 182 \\
$80-89$ & 149 \\
$90-99$ & 51 \\
\hline
\end{tabular}


The three most commonly used diagnoses of discharge, which are classified in ICD-10, are:

- Injury, poisoning and certain other consequences of external causes

(ICD-10 S00-T98): total number $789(59,2 \%)$

- Diseases of the musculoskeletal system and connective tissue (ICD-10

M00-M99): total number 354 (26,5\%)

- Neoplasms (ICD-10 C00-D48): total number $112(8,2 \%)$

Unless these data cannot indicate secondary diagnosis and pre-existing illness, additional data concerning dementia were requested. The total number of patients without a cognitive impairment are 1291 (96,89\%). 36 (2,7\%) have a slight cognitive impairment (Barthel-Index 70-90 points), 7 (0,5\%) have moderate cognitive impairment (Barthel-Index 20-65 points).

These data show a heterogeneous group of patients with different conditions (see Fig. 1).

\subsection{Technical solutions}

An assignment of technical solutions to the addressed issues shows that different technical solutions can be found (see Fig. 1). The field of medical and nursing technology offers solutions like mobilising mattresses or bed exit alert. But also other fields bring up solutions for nurses' needs such as robots for service issues, exoskeletons or a tracking system for medical assets.

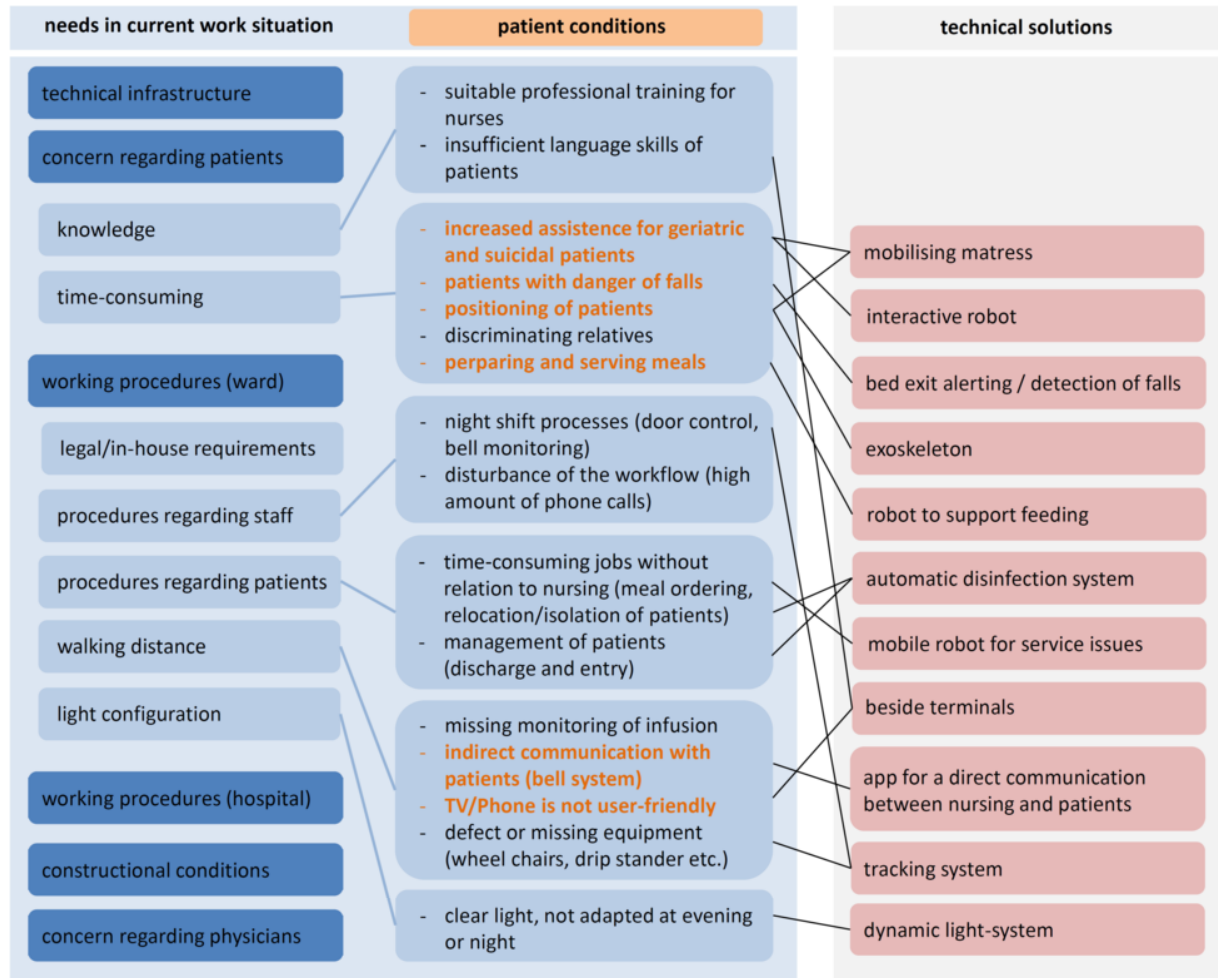

Figure 1. Overview of categories of nurses needs and possible technical solutions 


\section{Discussion}

These results show that in-house structures and processes at the healthcare sector, which affect the working procedures of professional nurses directly, have a significant stake in the nurses needs. In addition the majority of categories of the nurses needs are not appropriate for technical solutions. Focused on technical products the results indicate that different groups of users have to be considered. Beside the nurses and other staff, the patients are also affected by technical innovations as a special vulnerable and heterogeneous group. This makes an adapted and people-centered concept of implementation for each technical product necessary.

\section{Conclusions}

Even though the focus of the special field of trauma surgery has to be considered, these data show that the needs, nurses mentioned in the workshops, can be affirmed by secondary data of patients. These data do not identify nurses needs in general, but they provide basic information of their needs in a clinical setting and can support the process of the selection of technical solutions in other hospitals. First impressions of the ongoing implementation of technical products at the ward point out that available products have to be appropriate for the specific working process and well integrated. The critical factor here is the form and intensity of a participatory approach that accompanies the introduction of the technologies. Nevertheless, the reasonable application of technologies in the labour-intensiv nursing routine needs further discussion and research.

\section{References}

[1] Greenhalgh T, Abimbola S. The NASSS Framework-A Synthesis of Multiple Theories of Technology Implementation. Studies in health technology and informatics. 2019; 263:193-204.

[2] Huter K, Krick T, Domhoff D, Seibert K, Wolf-Ostermann K, Rothgang H. Effectiveness of digital technologies to support nursing care: results of a scoping review. Journal of Multidisciplinary Healthcare. 2020;13:1905 - 1926.

[3] Strutz N, Kuntz S, Lahmann N, et al. Analyse der Technikbereitschaft und -nutzung von Pflegeinnovationstechnologien von Mitarbeiter*innen im Pflegeprozess. HBScience. 2020;11:27-34.

[4] Sebastião M, Hechtel N, Krückeberg J. „In den Müll?!“ - Ursachenforschung zur Nicht-Nutzung technischer Innovationen in der stationären Pflege, Gesundheitswesen. 2020. Epub ahead of print.

[5] Krückeberg J, Klawunn R, Fuge I, Mazhari R, Schmeer R, Hechtel N. How to decide upon nursing technologies - a participation-based approach, Studies in Health Technology and Informatics.2020; 270.

[6] Rutz M, Schmeer R, Krückeberg J, Meyenburg-Altwarg I, Dierks ML. PPZ-Hannover - Methodische Überlegungen zur Baseline-Erhebung, Zukunft der Pflege: Tagungsband der Clusterkonferenz 2018. 2018.

[7] Kuckartz U. Qualitative Inhaltsanalyse: Methoden, Praxis, Computerunterstützung, Beltz Juventa, Weinheim, 2014.

[8] Krückeberg J, Rutz M, Hagen H, Hechtel N. Die Perspektive der Basis - Welche Bereiche in der stationären Pflege können von technischen Innovationen profitieren?, Zukunft der Pflege: Tagungsband der 2. Clusterkonferenz 2019. 